\title{
Severe Chloride Deficiency in the Neonate: The Canine Puppy as an Animal Model
}

\author{
CHRISTIAN C. FELDER, JEAN E. ROBILLARD, SHANE ROY III, AND PEDRO A. JOSE \\ Georgetown University Medical Center, Washington, D.C. 20007; University of Iowa Hospitals and Clinics, Iowa \\ City, Iowa 52242; University of Tennessee, Memphis, and LeBonheur Children's Medical Center,
}

Memphis, Tennessee 38103

\begin{abstract}
Studies were designed to develop an animal model for the syndrome of hypochloremic, hypokalemic metabolic alkalosis (HMA), and failure to thrive in infants due to intake of chloride-deficient formula. Littermate canine puppies, 2 wk old, were fed soy formula containing normal chloride, $20 \mathrm{mEq}$ /liter (NC, $n=5$ ), or low chloride, $1 \mathrm{mEq} /$ liter (LC, $n=5$ ) for $4 \mathrm{wk}$, first by gavage and $a d$ libitum thereafter. After 1 wk of LC formula, HMA developed in $\mathrm{LC}$ puppies although both $\mathrm{NC}$ and $\mathrm{LC}$ puppies had similar fluid and caloric intake and gain in weight and forelimb length. Two wk of $\mathrm{LC}$ formula also resulted in a higher serum creatinine and calcium but lower phosphate level in LC than NC puppies. After 4 wk of LC, weight and forelimb length were much less in LC than NC puppies. Plasma renin activity decreased with age in $\mathrm{NC}$ but remained elevated in LC. In a separate group of puppies ( $n$ = 6) with HMA, chloride supplementation of $\mathrm{LC}$ formula as $\mathrm{NaCl}$ to $\mathrm{NC}$ levels corrected HMA despite continued citrate intake. We conclude that the canine puppy is an appropriate model to study HMA due to decreased chloride intake. Low chloride intake independent of citrate caused the HMA. (Pediatr Res 21: 497-501, 1986)
\end{abstract}

\section{Abbreviations}

LC, low chloride

NC, normal chloride

CDS, chloride deficiency syndrome

HMA, hypochloremic metabolic alkalosis

PRA, plasma renin activity

BUN, blood urea nitrogen

$\mathrm{Cr}$, creatinine

Dietary CDS has been observed in infants fed a low chloride infant soy formula. The clinical features of the syndrome are failure to thrive, muscular weakness, anorexia, lethargy, vomiting, and dehydration. The laboratory features include hypochloremia, hypokalemia, hyponatremia, metabolic alkalosis, and increased plasma renin and aldosterone levels (1). A transient increase in serum calcium and phosphate levels also occurs during the early stages of the alkalosis (2) which could lead to the development of nephrocalcinosis (3-5).

Biochemical imbalances occurring as a result of dietary deficiency of chloride have been shown previously in laboratory animals (5-11) but the induction of HMA in neonatal animals has had limited success (13). It is believed that chloride ion

Received September 25, 1986; accepted December 17, 1986.

Correspondence Mr. Christian C. Felder, Georgetown University Hospital, Department of Pediatrics, 3800 Reservoir Road, NW, Washington, DC 20007.

Supported in part by the Infant Formula Council, Formula, the John Massaro Fund, and NIHHLBI grant HL 23081. depletion is responsible for the development of metabolic alkalosis and resultant electrolyte imbalances (9-11). Either citrate alone or in combination with other counter anions used to replace chloride in soy formulas has also been implicated in the development of HMA $(12,14)$.

Essential to the further study of CDS in human infants is a neonatal animal model that demonstrates the biochemical and clinical abnormalities characteristic of the disorder in infants. Therefore, the present study was primarily designed to develop a neonatal animal model of HMA. In addition, the role of chloride ion in the pathogenesis of HMA was evaluated.

\section{METHODS}

All experiments were carried out on littermate mongrel canine puppies randomly assigned to one of two formulas (Table 1) prepared under the direction of the Infant Formula Council to meet the dietary requirements of puppies (15). NC contained 20 $\mathrm{mEq} /$ liter chloride and the $\mathrm{LC}$ contained $1 \mathrm{mEq} /$ liter chloride. Both the LC and the NC formulas contained $20 \mathrm{mEq} / \mathrm{liter}$ of sodium with citrate added as the counter ion in the LC formula.

The formula containing $1 \mathrm{kcal} / \mathrm{ml}$ was fed to the puppies commencing $2 \mathrm{wk}$ following birth. Formula was fed by gavage every $6 \mathrm{~h}$ until the puppies were able to feed themselves, which occurred at about $6 \mathrm{wk}$ of age. At $6 \mathrm{wk}$ of age the animals were fed every $8 \mathrm{~h}$. Intake was monitored by measuring the amount of formula given and the amount of formula refused or regurgitated with each feeding. Formula was given to the puppies to assure caloric intake of about 160 to $225 \mathrm{kcal} / \mathrm{kg}$ per day.

Two litters of puppies were studied. The first litter (group I) had 10 puppies; five puppies were randomized to the LC group and five to the NC group. In order to determine further the role of chloride in HMA, another group of puppies (group II) was given the LC formula; after the establishment of HMA, chloride was supplemented in the LC formula to attain a chloride concentration similar to that found in the NC formula. This second litter (group II) had nine puppies; six puppies were assigned to LC formula and three to the NC formula. After 3 wk on the LC formula, at which time HMA was well established (see results Table 3), these puppies were fed the LC formula to which 19 $\mathrm{mEq} /$ liter chloride as $\mathrm{NaCl}$ had been added. The puppies were then fed the $\mathrm{NaCl}$-supplemented LC formula for the duration of the study.

Three $\mathrm{ml}$ of blood were collected from conscious animals every week. Sodium, $\mathrm{K}^{+}, \mathrm{Cl}^{-}$, and $\mathrm{HCO}_{3}{ }^{-}$were analyzed by ionspecific electrodes on a Beckman E4A Electrolyte analyzer. Urea nitrogen, creatinine, phosphate, and calcium were analyzed on a Dupont Automated Chemistry Analyzer. PRA was measured by radioimmunoassay (16). Right forelimb length was recorded weekly by measuring from the rear of the elbow to the front of the wrist with the paw bent at a $90^{\circ}$ angle to the forelimb. Weight was taken daily just prior to the $1200 \mathrm{~h}$ feeding to ensure at least a 6-h fast (before weaning) and an 8-h fast (after weaning). 
Table 1. Ingredients of $L C$ and $N C$ formulas: water, soy oil, soy protein isolate, coconut oil, lactose, minerals (calcium phosphate tribasic, potassium phosphate monobasic, magnesium chloride, potassium chloride, potassium citrate, sodium chloride, ferrous sulfate, zinc sulfate, potassium iodide), mono- and diglycerides, soy lecithin, vitamins (ascorbic acid, choline chloride, $\alpha$-tocopheryl acetate, niacinamide, calcium pantothenate, vitamin A palmitate, thiamine mononitrate, riboflavin, pyridoxine hydrochloride, phylloquinone, folic acid, biotin, vitamin $D_{3}$, cyanocobalamin) and L-methionine

\begin{tabular}{|c|c|c|c|}
\hline Nutrients & $\mathrm{LC}$ & $\mathrm{NC}$ & Wt/liter \\
\hline Protein & 45 & 45 & $\mathrm{~g}$ \\
\hline Fat & 78 & 78 & $\mathrm{~g}$ \\
\hline Carbohydrate & 30 & 30 & $\mathrm{~g}$ \\
\hline \multicolumn{4}{|l|}{ Minerals } \\
\hline Calcium & 1.4 & 1.4 & $\mathrm{~g}$ \\
\hline Phosphorus & 1.1 & 1.1 & $\mathrm{~g}$ \\
\hline Magnesium & 150 & 150 & $\mathrm{mg}$ \\
\hline Iron & 12 & 12 & $\mathrm{mg}$ \\
\hline Iodine & 100 & 100 & $\mu \mathrm{g}$ \\
\hline Zinc & 7 & 7 & $\mathrm{mg}$ \\
\hline Copper & 1 & 1 & $\mathrm{mg}$ \\
\hline Manganese & 100 & 100 & $\mu \mathrm{g}$ \\
\hline Sodium & 460 & 460 & $\mathrm{mg}$ \\
\hline Potassium & 1400 & 1400 & $\mathrm{mg}$ \\
\hline Chloride & 35 & 710 & $\mathrm{mg}$ \\
\hline Water & 837 & 837 & $\mathrm{~g}$ \\
\hline Crude fiber & 0 & 0 & \\
\hline $\mathrm{Cal} / \mathrm{fl} \mathrm{oz}$ & 30 & 30 & \\
\hline Cal/liter & 1000 & 1000 & \\
\hline \multicolumn{4}{|l|}{ Vitamins/liter } \\
\hline Vitamin A & 3000 & 3000 & IU \\
\hline Vitamin D & 600 & 600 & IU \\
\hline Vitamin E & 20 & 20 & IU \\
\hline Vitamin $\mathrm{K}_{1}$ & 100 & 100 & $\mu \mathrm{g}$ \\
\hline Vitamin C & 75 & 75 & $\mathrm{mg}$ \\
\hline Thiamine & 0.6 & 0.6 & $\mathrm{mg}$ \\
\hline Riboflavin & 0.9 & 0.9 & $\mathrm{mg}$ \\
\hline Vitamin $\mathrm{B}_{6}$ & 0.6 & 0.6 & $\mathrm{mg}$ \\
\hline Vitamin $\mathbf{B}_{12}$ & 10 & 10 & $\mu \mathrm{g}$ \\
\hline Niacin & 14 & 14 & $\mathrm{mg}$ \\
\hline Folic acid & 150 & 150 & $\mu \mathrm{g}$ \\
\hline Pantothenic acid & 7 & 7 & $\mathrm{mg}$ \\
\hline Biotin & 45 & 45 & $\mu \mathrm{g}$ \\
\hline Choline & 300 & 300 & $\mathrm{mg}$ \\
\hline L-Methionine & 300 & 300 & $\mathrm{mg}$ \\
\hline
\end{tabular}

Values are reported as the mean $\pm \mathrm{SE}$. Comparison between groups was analyzed by ANOVA and the results of the statistical analyses are shown in Table 4.

\section{RESULTS}

Serum $\mathrm{Na}^{+}, \mathrm{K}^{+}, \mathrm{Cl}^{-}, \mathrm{HCO}_{3}{ }^{-}, \mathrm{Ca}^{++}$, phosphorus, $\mathrm{BUN}, \mathrm{Cr}$, and PRA, as well as forelimb length and weight were similar in group I LC $(n=5)$ puppies at the time of randomization (Table 2; Figs. 1 and 2). The caloric intake was also similar. In group I $\mathrm{NC}$ puppies the $\mathrm{Na}^{+}, \mathrm{K}^{+}, \mathrm{Cl}^{-}$, and $\mathrm{HCO}_{3}{ }^{-}$concentrations did not decrease during the study. Serum $\mathrm{Ca}^{++}$, phosphorus, and PRA decreased between the 2nd and 4th wk of age. Weight slowly increased in the 3rd and 4th wk of age and rapidly increased after 4 wk of age (Fig 2, Tables 2 and 4). Forelimb lengths increased with age. The increments in weight gain in group I NC puppies were similar to those described in bitch nursed puppies (15). Caloric intake averaged $160 \mathrm{kcal} / \mathrm{kg}$ per day for the initial feeding and then increased with age.

After a week on the LC formula, group I LC puppies had higher serum $\mathrm{HCO}_{3}{ }^{-}$and lower $\mathrm{Na}^{+}, \mathrm{K}^{+}, \mathrm{Cl}^{-}$levels than the $\mathrm{NC}$ group (Fig. 1). This occurred despite similar fluid and caloric intake and weight. By the 2nd wk of LC formula (4 wk of age), serum creatinine, and calcium were higher and serum phospho-
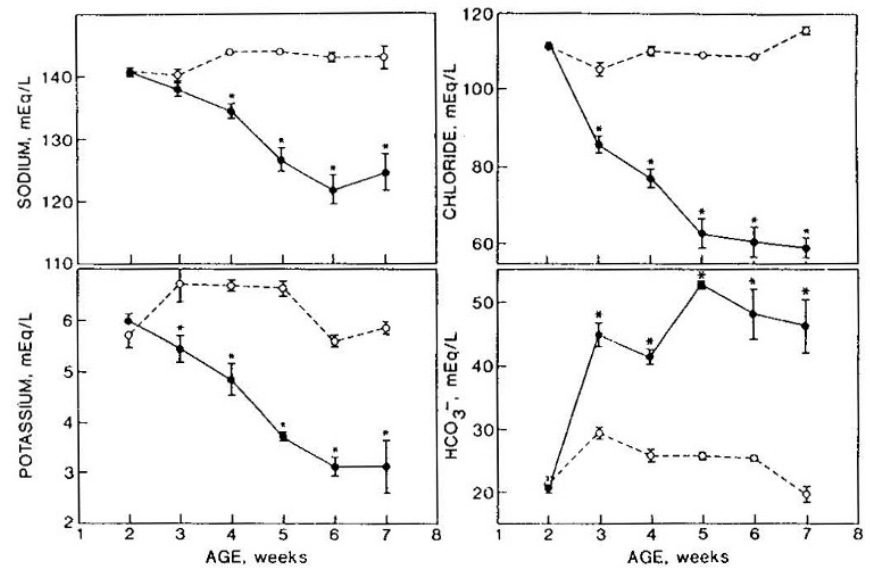

Fig. 1. Serum electrolyte concentrations in group I puppies fed normal chloride (NC, $n=5)$ formula (O- $--\mathrm{O}$ ) or low chloride (LC, $n=5$ ) formula (- - ). Data are presented as mean $\pm \mathrm{SE}$. SE is not depicted in cases where the symbol encompasses SE values. ${ }^{*} p<0.05$ versus 2 wk, analysis of variance. For additional statistical analyses, see Table 4A (group I puppies).

Table 2. Caloric intake, serum chemistries, and growth parameters in group I puppies fed NC formula $(n=5)$ and puppies fed LC formula $(n=5)$ during development (mean $\pm S E, 1 \mathrm{kcal}=1$ - $\mathrm{ml}$ formula)

\begin{tabular}{|c|c|c|c|c|c|c|}
\hline \multirow[b]{2}{*}{ Age (wk) } & \multicolumn{3}{|c|}{$\mathrm{NC}$} & \multicolumn{3}{|c|}{$\mathrm{LC}$} \\
\hline & 2 & 4 & 6 & 2 & $4^{*}$ & $6^{*}$ \\
\hline $\mathrm{Na}^{+}, \mathrm{mEq} / \mathrm{liter}$ & $141 \pm 0.6$ & $143 \pm 0.4$ & $143 \pm 0.3$ & $141 \pm 0.7$ & $134 \pm 1.0$ & $123 \pm 2.3$ \\
\hline $\mathrm{Cl}^{-}, \mathrm{mEq} /$ liter & $110 \pm 0.5$ & $109 \pm 1$ & $109 \pm 0.4$ & $111 \pm 0.7$ & $77 \pm 2$ & $58 \pm 2$ \\
\hline $\mathrm{HCO}_{3}{ }^{-}, \mathrm{mEq} /$ liter & $21.3 \pm 1.0$ & $25.7 \pm 1.0$ & $25.3 \pm 0.3$ & $20.7 \pm 0.7$ & $41.5 \pm 1.0$ & $48.4 \pm 3.6$ \\
\hline $\mathrm{BUN}, \mathrm{mg} / \mathrm{dl}$ & $21 \pm 2$ & $11 \pm 2$ & $13 \pm 1$ & $21 \pm 2$ & $16 \pm 2$ & $74 \pm 20$ \\
\hline $\mathrm{Cr}, \mathrm{mg} / \mathrm{dl}$ & & $0.24 \pm 0.02$ & $0.24 \pm 0.02$ & & $0.43 \pm 0.02$ & $0.73 \pm 0.1$ \\
\hline Wt, g & $723 \pm 67$ & $1008 \pm 62$ & $2119 \pm 129$ & $779 \pm 45$ & $960 \pm 68$ & $973 \pm 106$ \\
\hline Forelimb length, $\mathrm{cm}$ & $5.9 \pm 0.2$ & $6.8 \pm 0.2$ & $8.2 \pm 0.2$ & $6.2 \pm 0.2$ & $6.9 \pm 0.2$ & $7.2 \pm 0.3$ \\
\hline $\mathrm{kcal} / \mathrm{kg}$ & $160.1 \pm 1.5$ & $199.6 \pm 19.7$ & $225.2 \pm 19.1$ & $166.1 \pm 1.4$ & $206.4 \pm 5.9$ & $106.3 \pm 6.0$ \\
\hline $\mathrm{PRA}, \mathrm{ng} / \mathrm{ml}$ & $34.7 \pm 4.1$ & $22.0 \pm 4.1$ & $7.2 \pm 1.1$ & $47.4 \pm 11.2$ & $99.1 \pm 16.5$ & $37.4 \pm 10.8 \dagger$ \\
\hline
\end{tabular}

${ }^{*} n=4$ (one LC puppy with the most severe HMA died at 3 wk of age).

$\dagger n=3$. 


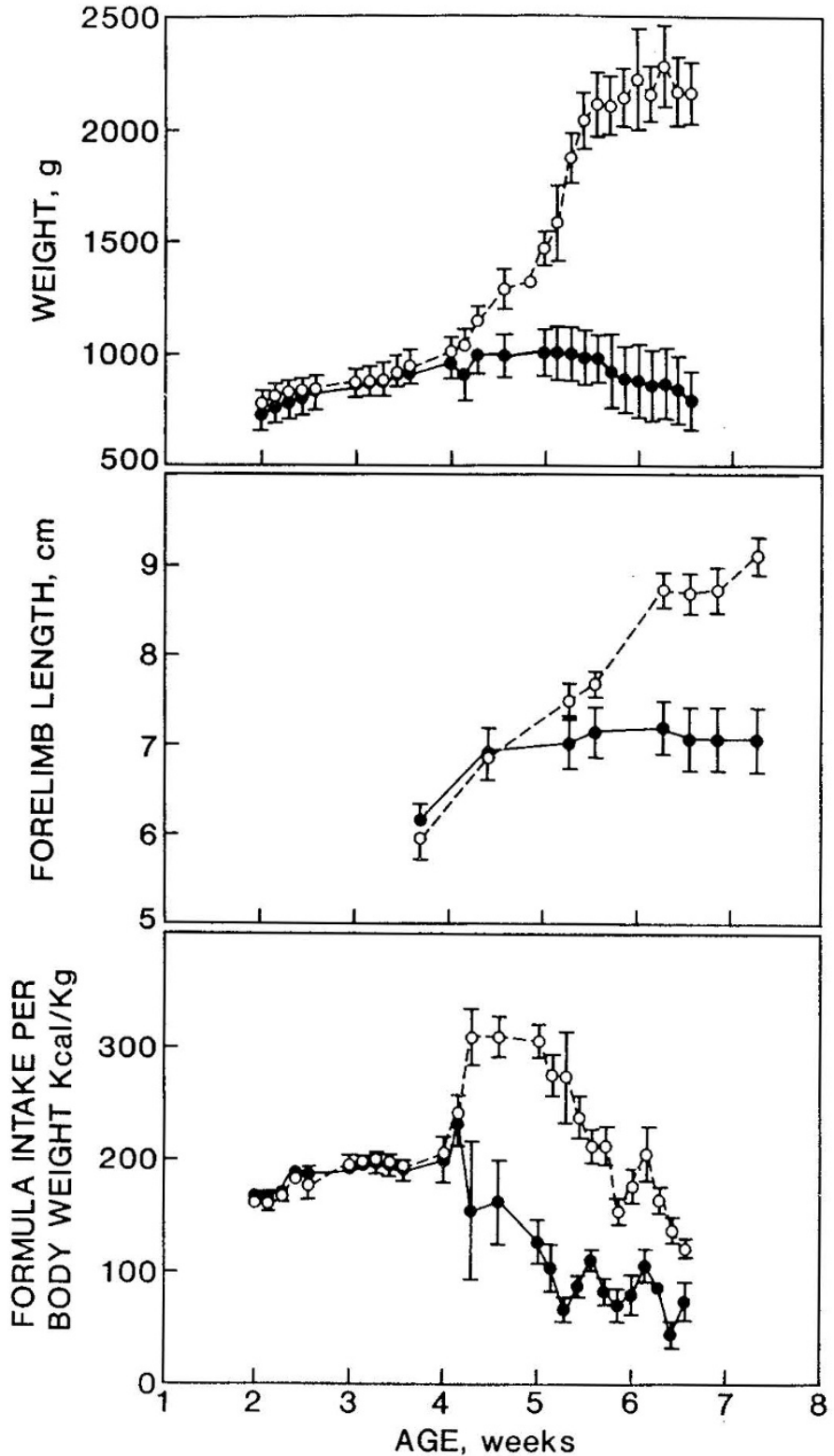

Fig. 2. Weight, forelimb length, and caloric intake in group I puppies fed normal chloride (NC, $n=5$ ) formula $\left(\mathrm{O}_{-}--\mathrm{O}\right.$ ) or low chloride (LC, $n=5$ ) formula ( - Data are presented as mean \pm SE. For statistical analyses see Table 4A (group I puppies). rus levels lower in $\mathrm{LC}$ compared to $\mathrm{NC}$ puppies. While $\mathrm{HCO}_{3}{ }^{-}$ levels seemed to stabilize after the first 2 wk of $\mathrm{LC}$ feeding, $\mathrm{Na}^{+}$, $\mathrm{K}^{+}, \mathrm{Cl}^{-}$, and phosphorus continued to decrease but leveled off at 5 to $7 \mathrm{wk}$ of age. Serum calcium levels which were higher in LC than NC after 2 wk of LC (4 wk of age) were no longer different from the NC puppies after $4 \mathrm{wk}$ of LC intake (6 wk of age) (Tables 2 and 4). PRA markedly increased 2 wk after initiation of LC diet and remained elevated over the duration of the study (Table 2). In contrast PRA decreased with age in NC puppies.

After $2 \frac{1}{2}$ wk of LC formula intake or by $4 \frac{1}{2}$ wk of age the weight of the LC puppies was less than that of the NC puppies (Fig. 2). NC puppies displayed exponential weight increases while LC puppies gained less than half the weight of the NC puppies at $6 \mathrm{wk}$ of age (Fig. 2). In contrast to the weight, the forelimb length differences did not become apparent until $5 \frac{1 / 2}{2 \mathrm{k}}$ of age (Fig. 2). These differences were magnified after $4 \mathrm{wk}$ of LC formula ( $6 \mathrm{wk}$ of age). After $2 \frac{1 / 2}{2} \mathrm{wk}$ of LC formula intake (41/2 wk of age) the caloric intake was less in the LC puppies than the NC puppies because of formula regurgitation (Fig. 2). A puppy in group I LC with the most severe HMA died at 3 wk of age. All puppies were weaned at 6 wk of age. The LC group was lethargic and lacked interest in food. During later stages of the HMA the puppies exhibited weakness, difficulty in standing, and irregular walking and breathing. Puppies with HMA (LC puppies) regurgitated milk (less than $5 \%$ of the intake) after each feeding.

To determine further the role of chloride in the development and maintenance of HMA, another group of puppies was studied. Group II NC $(n=3)$ and LC $(n=6)$ puppies had similar serum $\mathrm{Na}^{+}, \mathrm{K}^{+}, \mathrm{Cl}^{-}, \mathrm{HCO}_{3}{ }^{-}, \mathrm{BUN}, \mathrm{Cr}, \mathrm{Ca}^{++}$, and phosphorus and similar weights and forelimb lengths at the time of randomization (Tables 3 and 4; Fig. 3). Group II NC puppies behaved in a similar fashion as group I NC puppies with the exception that $\mathrm{Ca}^{++}$, phosphorus, and BUN levels did not change with age. Increments in weight and forelimb length were also less compared to group I NC. Caloric intake was initially greater in group II than group I puppies but was similar by $4 \mathrm{wk}$ of age. In contrast to group I LC puppies which developed metabolic alkalosis after $1 \mathrm{wk}$, the group II LC puppies developed metabolic alkalosis after 2 wk of LC formula. After $3 \mathrm{wk}$ on the LC formula (5 wk of age), and after 1 wk of HMA, $19 \mathrm{mEq} /$ liter of $\mathrm{Cl}$ in the form of $\mathrm{NaCl}$ was added to the LC formula (Fig. 3). After $1 \mathrm{wk}$ of $\mathrm{NaCl}$ supplementation in $\mathrm{LC}$, there was a marked increase in serum $\mathrm{Na}^{+}, \mathrm{K}^{+}$, and $\mathrm{Cl}^{-}$, with a marked decrease in serum $\mathrm{HCO}_{3}{ }^{-}$(Fig. 3; Tables 3 and 4). In contrast to group I where LC puppies with HMA had higher serum calcium levels at 4 wk of age, group II LC and NC puppies had similar serum $\mathrm{Ca}^{++}$levels at $5 \mathrm{wk}$ of age. Serum phosphorus was lower in LC than NC

Table 3. Caloric intake, serum chemistries, and growth parameters in group II puppies fed NC formula ( $n=3)$ and puppies fed LC formula $(n=6)$ during development; $\mathrm{NaCl}$ supplementation begun at 5 wk of age ( $\mathrm{NaCl} 19 \mathrm{mEq} / \mathrm{liter}$ added to LC formula), 2 wk after development of HMA

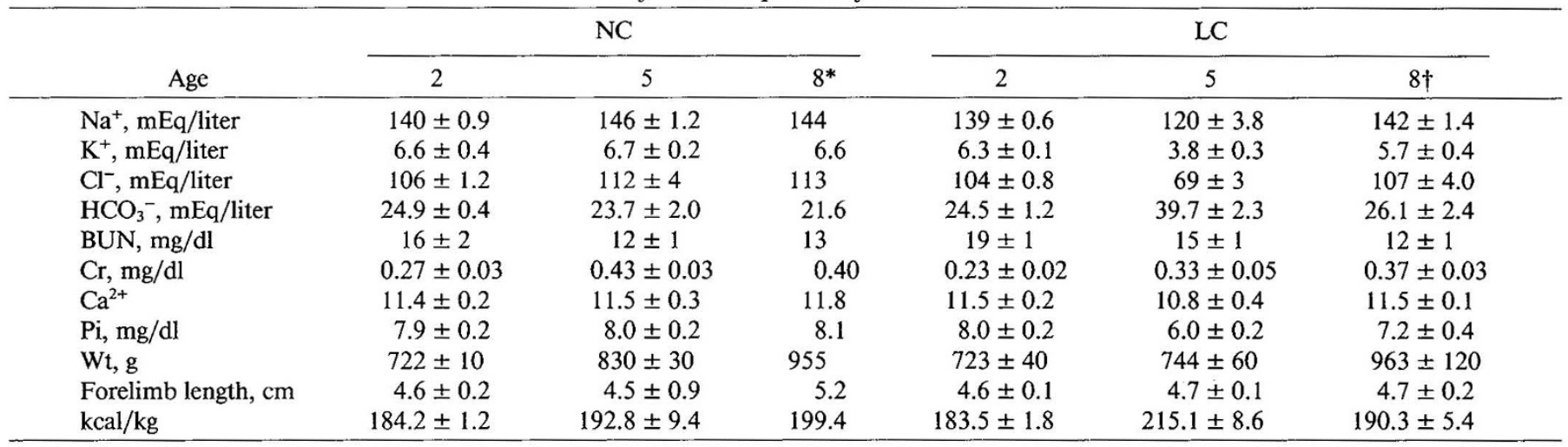

$* n=2$ (one NC group II puppy died accidentally at $6 \mathrm{wk}$ of age).

$\dagger n=3$ (three LC group II puppies with HMA died at $6-71 \frac{1}{2}$ wk of age). 
Table 4A. $p$ values for Table 2, group I puppies (analysis of variance)

\begin{tabular}{|c|c|c|c|c|c|c|c|}
\hline \multirow[b]{3}{*}{ Formula Age (wk) } & \multicolumn{7}{|c|}{ Group I } \\
\hline & \multicolumn{2}{|c|}{$\mathrm{NC}$} & \multicolumn{2}{|c|}{ LC } & \multicolumn{3}{|c|}{$\mathrm{NC} v s \mathrm{LC}$} \\
\hline & $2 v s 4$ & 4 vs 6 & $2 v s 4$ & 4 vs 6 & 2 & 4 & 6 \\
\hline $\mathrm{K}^{+}, \mathrm{mEq} /$ liter & 0.01 & 0.01 & 0.01 & 0.01 & NS & 0.01 & 0.01 \\
\hline $\mathrm{Cl}^{-}, \mathrm{mEq} / \mathrm{liter}$ & NS & NS & 0.01 & 0.01 & NS & 0.01 & 0.01 \\
\hline $\mathrm{HCO}_{3}{ }^{-}, \mathrm{mEq} /$ liter & NS & NS & 0.01 & 0.01 & NS & 0.01 & 0.01 \\
\hline $\mathrm{Ca}^{2+}, \mathrm{mg} / \mathrm{dl}$ & 0.01 & NS & NS & 0.01 & NS & 0.01 & NS \\
\hline $\mathrm{Pi}, \mathrm{mg} / \mathrm{dl}$ & 0.01 & NS & 0.01 & 0.01 & NS & 0.01 & 0.01 \\
\hline $\mathrm{Wt}, \mathrm{g}$ & 0.01 & 0.01 & 0.01 & NS & NS & NS & 0.01 \\
\hline Forelimb length, $\mathrm{cm}$ & 0.01 & 0.01 & 0.01 & NS & NS & NS & 0.01 \\
\hline $\mathrm{kcal} / \mathrm{kg}$ & 0.01 & 0.01 & 0.01 & 0.01 & NS & 0.01 & 0.01 \\
\hline PRA, ng/ml & 0.01 & 0.01 & 0.01 & 0.01 & NS & 0.01 & 0.01 \\
\hline
\end{tabular}

Table 4B. $p$ values for Table 3, group II puppies (analysis of variance)

\begin{tabular}{|c|c|c|c|c|c|c|}
\hline \multirow[b]{3}{*}{ Formula Age (wk) } & \multicolumn{6}{|c|}{ Group II } \\
\hline & \multirow{2}{*}{$\frac{\mathrm{NC}}{2 v s 5}$} & \multicolumn{3}{|c|}{ LC } & \multicolumn{2}{|c|}{$\mathrm{NC}$ vs $\mathrm{LC}$} \\
\hline & & 2 vs 5 & 5 vs 8 & 2 vs 8 & 2 & 5 \\
\hline $\mathrm{K}^{+}, \mathrm{mEq} / \mathrm{liter}$ & NS & 0.01 & 0.01 & NS & NS & 0.01 \\
\hline $\mathrm{Cl}^{-}, \mathrm{mEq} / \mathrm{liter}$ & 0.01 & 0.01 & 0.01 & NS & NS & 0.01 \\
\hline $\mathrm{HCO}_{3}{ }^{-}, \mathrm{mEq} /$ liter & NS & 0.01 & 0.01 & NS & NS & 0.01 \\
\hline $\mathrm{Ca}^{2+}, \mathrm{mg} / \mathrm{dl}$ & NS & 0.01 & NS & NS & NS & NS \\
\hline $\mathrm{Pi}, \mathrm{mg} / \mathrm{dl}$ & NS & 0.01 & 0.01 & NS & NS & 0.01 \\
\hline $\mathrm{Wt}, \mathrm{g}$ & 0.01 & NS & 0.01 & $*$ & NS & 0.01 \\
\hline Forelimb length, $\mathrm{cm}$ & NS & NS & NS & NS & NS & NS \\
\hline $\mathrm{kcal} / \mathrm{kg}$ & 0.01 & 0.01 & 0.01 & NS & NS & NS \\
\hline
\end{tabular}

* NS by analysis of variance, $p<0.05$ by paired $t$ test.

puppies at 5 wk of age (Tables 3 and 4). After 3 wk of $\mathrm{NaCl}$ supplementation, serum chemistries approximated group II NC values. Three group II LC puppies with HMA died between 6$7 \frac{1}{2}$ wk of age. Catch-up in weight but not in forelimb length occurred in LC (Table 3).

\section{DISCUSSION}

In the present study we raised canine puppies with a soy formula prepared by The Infant Formula Council that appeared to provide a balanced source of nutrition similar to that received by naturally nursed puppies (15).

Severe HMA developed in both group I and II LC puppies during the first 2 wk on the LC formula even though weight, forelimb length, and caloric intake were similar. When group II LC puppies were supplemented with $\mathrm{NaCl}$ to chloride levels similar to that of NC puppies, the serum bicarbonate returned close to NC levels. The hypochloremia, hypokalemia, and hyponatremia induced by the LC formula also returned to NC levels. Similar results have been observed in adult animal models (911) yet no completely successful attempt has been made in a neonatal animal (13). In piglets, low chloride formula produced HMA but without hypokalemia (13). In the adult models a combination of a low chloride intake, and loop diuretic or peritoneal dialysis was usually necessary to induce HMA of a milder nature compared to our neonatal model (7-11). Hyponatremia is not a frequent finding in CDS in adult animal models (8-11) despite diuretic therapy to enhance the volume depletion. However, the puppies consistently developed hyponatremia with the development of HMA. Although the mechanism for the hyponatremia in these puppies was not studied, renal sodium
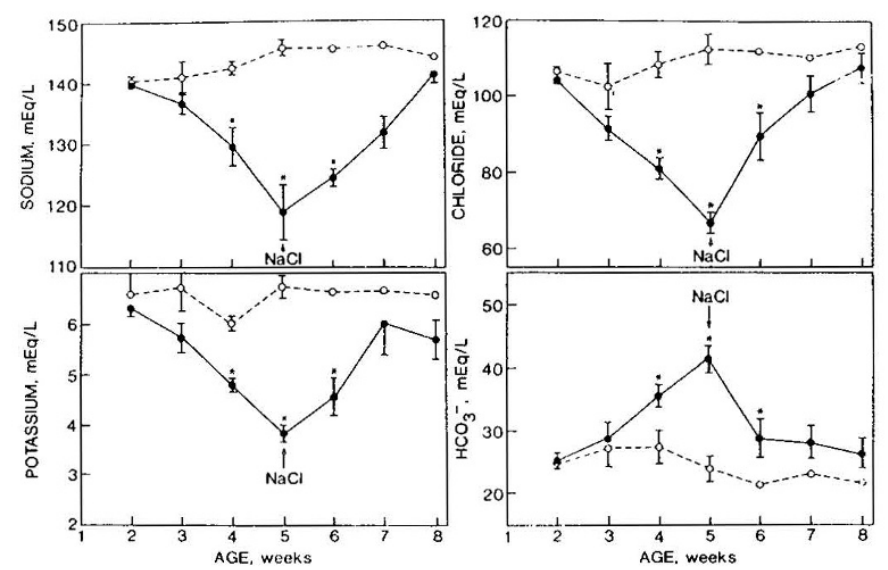

Fig. 3. Serum electrolyte concentrations in group II puppies fed normal chloride formula (O- - $\mathrm{O})(\mathrm{NC}, n=3,2-5 \mathrm{wk}, n=2$ thereafter; one puppy died accidentally at $6 \mathrm{wk}$ ) or low chloride formula ((LC, $n=6,2-5$ wk, $n=3$ thereafter, three puppies with HMA died at $6-71 \frac{1}{2}$ wk of age). Data are presented as mean \pm SE. There were only two remaining control puppies at $6-8 \mathrm{wk}$ of age, thus $\mathrm{SE}$ were not calculated. ${ }^{*} p<0.05$ versus $2 \mathrm{wk}$, analysis of variance.

losses may have been responsible for the hyponatremia. It is possible that an immature ascending loop of Henle is unable to compensate for the increased sodium bicarbonate load (17). These studies demonstrate that canine puppies can be used successfully as a neonatal animal model for the study of HMA due to intake of chloride deficient soy formula $(1,2,14)$. 
The mechanism of the development and maintenance of metabolic alkalosis secondary to chloride deficiency has yet to be completely understood. The deficiency of chloride ion appears to play a central role in the development of the metabolic alkalosis as well as the subsequent biochemical changes that occur (11).

Selected chloride depletion is a powerful stimulus to renin and aldosterone release (18). Aldosterone stimulates hydrogen ion secretion and bicarbonate reabsorption and serves to maintain the metabolic alkalosis. Although serum aldosterone levels were not measured in our studies, PRA levels were higher in LC than NC puppies. PRA decreases with age in NC puppies, whereas PRA levels remained elevated in the LC group.

Cogan and Liu (19) have suggested that HMA is maintained by a decrease in GFR and helps to maintain the HMA. However, Maddox and Gennari (8) have shown that metabolic alkalosis can be maintained despite restoration of glomerular filtration rate to normal levels (8). They suggested that HMA is maintained by increases in bicarbonate reabsorption by tubular hypertrophy, chronic adaptive response, or load-dependent response. Glomerular filtration rate was not measured in our experiments, but the serum creatinine level was higher in group I LC puppies than group I NC puppies after $2 \mathrm{wk}$ of $\mathrm{LC}$ formula suggesting that a decreased glomerular filtration rate played a role in maintaining the metabolic alkalosis in these puppies similar to the mechanism suggested by Cogan and Liu (19). In group II puppies, serum creatinine was similar in NC and LC even after 1 wk of HMA suggesting that a decrease in glomerular filtration rate was not important in maintaining the metabolic alkalosis in group II LC puppies.

Volume depletion was initially thought to be the dominant mechanism of the maintenance of HMA (12). However, recent studies have demonstrated chloride depletion alkalosis in the absence of volume depletion and correction of chloride depletion alkalosis without volume expansion $(10,11)$. Although extracellular fluid volume was not measured in our studies, weight and flluid intake were similar in the NC and LC puppies at a time when HMA was already evident.

Citrate has been suggested as providing sufficient alkali to generate the alkalosis associated with the intake of chloridedeficient soy formula (14). Although the contribution of citrate to the generation of HMA cannot be quantitated in our studies, the fact that chloride replenishment despite continued citrate intake normalized serum bicarbonate levels suggest that factors other than citrate were responsible for the maintenance and correction phases of HMA.

Hypokalemia, due to increased renal losses, occurs in HMA $(10,20)$. The hypokalemia that accompanies HMA has been implicated in sustaining the metabolic alkalosis by increasing proximal tubular bicarbonate reabsorption (21). However, Maddox and Gennari (8) showed no difference in the relationship between filtered load and proximal bicarbonate reabsorption between normokalemic and hypokalemic rats. It is unlikely that potassium played a primary role in the maintenance of HMA since the HMA and hypokalemia were corrected with $\mathrm{NaCl}$ supplementation without added potassium.

Human infants fed chloride-deficient infant soy formula developed hypercalcemia and hyperphosphatemia (2). In our studies transient elevation in serum calcium was noted in group I but not group II LC puppies. Hyperphosphatemia was not observed in our puppies; serum phosphorus actually decreased progressively throughout the study period in LC puppies. HMA has been associated with nephrocalcinosis in CDS in rats $(3,4)$ and human infants (22), as well as in congenital chloride diarrhea (23) and Bartter's syndrome $(24,25)$. Whether the transient hypercalcemia is important in the pathogenesis of nephrocalcinosis remains to be determined.
Group I and group II puppies on the LC formula failed to thrive as evidenced by decreased weight gain and stunted forelimb growth. The decreased weight gain but not the stunted growth of the forelimb in group II LC puppies was reversed by chloride replenishment. It is possible that catch-up in forelimb length would also have occurred if the duration of the study had been extended.

We conclude that the canine puppy is an appropriate model to study HMA secondary to decreased chloride intake. Further studies to completely understand the mechanisms of the development and maintenance of HMA secondary to chloride deficient intake are warranted.

Acknowledgments. The authors acknowledge the assistance of Dr. Charles L. Stewart and Dr. Mouin G. Seikaly.

\section{REFERENCES}

1. Roy S III 1984 The chloride depletion syndrome. Adv Pediatr 31:235-257

2. Soriano JR, Vallo A, Castillo G, Oliveros R, Cea TM, Balzategui MJ 1983 Biochemical features of dietary chloride deficiency syndrome: a comparative study of thirty cases. J Pediatr 103:209-214

3. Levine DZ, Roy D, Tolnai G, Nash L, Shah BG 1974 Chloride depletion and nephrocalcinosis. Am J Physiol 227:878-883

4. Sakar K, Tolnai G, Levine DZ 1973 Nephrocalcinosis in chloride depleted rats. Calcif Tissue Res 12:1-7

5. Lowenhaupt E, Greenberg DM 1946 Renal changes associated with a chloride deficient diet in the rat. Arch Pathol 42:49-55

6. Greenberg DM, Cuthbertson EM 1942 Dietary chloride deficiency and alkalosis in the rat. J Biol Chem 145:179-189

7. Khanh BT, Luke RG 1976 Chloride depletion and hypochloremia as a cause of renal sodium loss and water in the rat. Clin Sci Mol Med 51:353-362

8. Maddox DA, Gennari FJ 1986 Load dependence of proximal tubular bicarbonate reabsorption in chronic metabolic alkalosis in the rat. J Clin Invest 77:709-716

9. Galla JH, Bonduris DN, Dumbauld SL, Luke RG 1984 Segmental chloride and fluid handling during correction of chloride-depletion alkalosis without volume expansion in the rat. J Clin Invest 73:96-106

10. Craig DM, Galla JH, Bonduris DN, Luke RG 1986 Importance of the kidney in the correction of chloride-depletion alkalosis in the rat. Am J Physio 250:F54-F57

11. Luke RG, Galla JH 1983 Chloride-depletion alkalosis with a normal extracellular fluid volume. Am J Physiol 14:F419-F424

12. Schwartz WB, Cohen JJ 1978 The nature of the renal response to chronic disorders of acid base equilibrium. Am J Med 64:417-428

13. Frattali V, Khan M, Dymsza H, Vessey A, Sager A, Miller E 1982 Chloride deficiency in the miniature piglet. Fed Proc 41:772(abstr)

14. Linshaw MA, Harrison HL, Gruskin AB, Prebis J, Harris J, Stein R, Jayaram MR, Preston D, DiLiberti HJ, Baluarte JH, Elzouki A, Carroll N 1980 Hypochloremic alkalosis in infants associated with soy protein formula. $\mathbf{J}$ Pediatr 96:635-640

15. Mosier JE 1978 The puppy from birth to six weeks. Vet Clin North Am 8:5378

16. Haber E, Koerner T, Page LB 1969 Application of a radioimmunoassay for angiotensin I to the physiologic measurements of plasma renin activity in normal human subjects. J Clin Endocrinol 29:1349-1355

17. Horster M 1982 Expression of ontogeny in individual nephron segments. Kidney Int 22:550-559

18. Abboud HE, Luke RG, Galla JH, Kotchen TA 1979 Stimulation of renin by acute selective chloride depletion in the rat. Circ Res 44:815-838

19. Cogan MG, Liu FY 1983 Metabolic alkalosis in the rat. Evidence that reduced glomerular filtration rather than enhanced tubular bicarbonate reabsorption is responsible for maintaining the alkalotic state. J Clin Invest 71:1141-1160

20. Giebisch GG, Malnic G, Berliner RW 1986 Renal transport and control of potassium excretion. In: Brenner BM, Rector FG (eds) The Kidney, 3rd ed. WB Saunders Co, Philadelphia, pp 177-205

21. Chan YL, Biagi B, Giebisch G 1982 Control mechanisms of bicarbonate transport across the rat proximal convoluted tubule. Am J Physiol 242:F532F543

22. Roy S III, Arant BS Jr 1981 Hypokalemic metabolic alkalosis in normotensive infants with elevated plasma renin activity and hyperaldosteronism: Role of dietary chloride deficiency. Pediatrics 67:423-435

23. Holmberg C, Perheentupa J, Pasternack A 1977 The renal lesion in congenital chloride diarrhea. J Pediatr 91:738-746

24. Fanconi A, Schachenmann G, Nussli R, Prader A 1971 Chronic hypokalemia with growth retardation, normotensive hyperrenin-hyperaldosteronism (Bartter's syndrome) and hypercalciuria. Helv Pediatr Acta 26:144-152

25. McCredie DA, Rotenberg E, William AL 1974 Hypercalciuria in potassiumlosing nephropathy: a variant of Bartter's syndrome. Aust Paediatr J 10:286299 